\title{
Formação ativa e expressiva de professores: "bagunçando o coreto" para estimular a inclusão!
}

\author{
Luzia Mara Silva Lima-Rodrigues*
}

\section{Resumo}

O professor pode ter tecnologia à sua disposição, pode dispor as cadeiras em círculos ou até conhecer várias ferramentas de intervenção, mas, sem um profundo desenvolvimento pessoal ligado à Inclusão, as suas ações tenderão a estar distantes de uma Educação equitativa, de qualidade e para todos. Este artigo analisa o curso de formação contínua "Pedagogias Expressivas em Educação Inclusiva", realizado em 10 ediçôes, em Portugal, nos últimos 3 anos. O curso foi delineado com duas intenções: estimular os formandos a utilizar as Pedagogias Expressivas nas suas práticas educativas e utilizar as Pedagogias Expressivas para dar aos participantes uma formação pessoal, com impacto nas suas práticas educativas em favor da Inclusão. A análise dos relatórios apresentados pelos formandos dividiu-se em três categorias: as reflexôes sobre o reconhecimento de si, as reflexóes sobre o reconhecimento do e a interação com o outro, e as reflexóes sobre a prática profissional. Desta análise resulta, sobretudo, que os formandos julgam ser fundamental "olhar para dentro de si" para integrar melhor o desenvolvimento pessoal com o profissional; em segundo lugar, assumem que a inversão de papeis com os diversos intervenientes do processo educativo permite um melhor conhecimento dos mesmos e leva a uma maior empatia, sendo esta fundamental para uma prática profissional mais inclusiva; e, por fim, os formandos identificam que o forte impacto da formaçáo no seu desempenho profissional está no fato de o curso utilizar uma metodologia que aguça a reflexão sobre dimensão pessoal de cada um, tornando-a numa formação que, de certa forma, "incita a Inclusão".

Palavras-chave: Pedagogias expressivas; Formação de professores; Educação inclusiva.

\footnotetext{
* Professora da Escola Superior de Educação do Instituto Politécnico de Satúbal e Diretora Executiva da Vindas Educação Internacional, Portugal.
} 


\section{Active and expressive teacher's training: messing up the class to stimulate inclusion}

\section{Abstract}

The teacher may have technology at his disposal, may arrange chairs in circles or know various intervention tools but, without a deep personal development connected to Inclusion, his actions will tend to be far from an equitable education, with high quality and for all. This article analyzes the teacher education course "Expressive Pedagogies in Inclusive Education", held in Portugal over the last 3 years. The course was designed with two intentions: to encourage trainees to use Expressive Pedagogies in their educational practices and to use Expressive Pedagogies to give participants a personal formation with an impact on their educational practices for Inclusion. The analysis of the reports presented by the trainees was divided into three categories: reflections on self-recognition, reflections on recognition of and interaction with one another, and reflections on professional practice. The results, above all, shows that the trainees consider essential to "look within themselves" in order to better integrate personal and professional development; second, they assume that the role reversal with the various actors in the educational process allows a better knowledge of them and leads to greater empathy, which is fundamental for a professional practice more inclusive; and, finally, the trainees identify that the strong impact of this course on their professional performance lies in the fact that it use a methodology that promotes the reflection about the personal dimension, transforming it into a course that, in certain way, "incites Inclusion".

Keywords: Expressive pedagogies; Teacher education; Inclusive education.

... existe uma "forma de ser" essencial para a prática inclusiva, a qual não é conseguida através da transmissão de conhecimento ou assinalada numa lista de competências. (EADSNE, 2011, 34p.)

\section{A formação contínua "Pedagogias Expressivas em Educação Inclusiva"}

O objetivo deste artigo é apresentar uma análise do curso de formação contínua "Pedagogias Expressivas em Educação Inclusiva" e mostrar um exemplo de como uma formação de professores pode mudar ou incitar/potenciar/estimular/impulsionar/acelerar a mudança de atitudes em favor da Inclusão.

Trata-se de um curso com 25 horas de duração, realizado entre os anos de 2014 e 2016 por 193 formandos, distribuídos em 10 diferentes ediçóes do mesmo curso: 8 ediçốes promovidas pelo Centro de Formação da Pró-Inclusão: Associação Nacional de Docentes de Educação Especial, 1 edição pelo Centro de Formação "Os Templários” e 1 edição pela Direção Regional de Ensino da Região Autónoma da Madeira, tendo lugar nas cidades de Lisboa, Almada, Porto, Tomar e Miranda do Corvo, em Portugal continental, e na cidade do Funchal, na Ilha da Madeira. 
Todas as ediçôes do curso foram acreditadas pelo Conselho Científico-Pedagógico da Formação Contínua - a quem compete a acreditação das ações de formação contínua de professores, das entidades formadoras e dos cursos de formação especializada de Portugal - contabilizando (um) crédito de formação para fins de progressão da carreira docente.

As inscrições dos formandos nas diversas edições do curso aconteceram de duas maneiras distintas: por inscrição individual, quando a edição era divulgada publicamente e permitia a participação de qualquer profissional interessado, ou por inscrição de um grupo, quando a ediçáo era destinada a profissionais de uma mesma escola ou projeto. As ediçóes foram sempre oferecidas por um Centro de Formação e foram realizadas dentro de uma escola, com exceção da edição que aconteceu na Ilha da Madeira, que utilizou os espaços próprios da entidade promotora do curso.

As aulas decorriam maioritariamente em salas onde as mesas e cadeiras pudessem ser deslocadas, como salas de judô, salas de expressōes, bibliotecas ou ginásios. Em alguns momentos foram utilizadas também as salas de aula regulares e alguns espaços exteriores, como jardins ou pátios.

Os formandos eram predominantemente Educadores de Infância, Professores do Ensino Básico e do Ensino Secundário ${ }^{1}$ e Professores de Educaçáo Especial, contando também com a participação de psicólogos, psicomotricistas, animadores socioculturais, terapeutas da fala ${ }^{2}$ e outros técnicos e profissionais ligados à Educação Inclusiva.

\section{"lugar" da formação}

O curso de formação contínua analisado neste artigo acontece em Portugal. Apresentar o "lugar", onde a formação acontece é essencial para contextualizá-la, ainda que de forma panorâmica, limitada e seguindo um assumido ponto de vista.

Dito isto, Portugal é um país europeu com 10 milhôes de habitantes, situado no extremo ocidental da Península Ibérica e que tem se destacado pelos avanços significativos e consistentes no âmbito da Educação, da Inclusão e da justiça social. Em 2017, por exemplo, foi considerado o terceiro país mais pacífico do mundo segundo o Global Peace Index (INSTITUTE FOR ECONOMICS \& PEACE, 2017), ficando atrás apenas da Islândia e da Nova Zelândia. No campo da Educação, a despesa total com a Educação obrigatória em Portugal teve um aumento de 33\%, entre 2008 e 2013, apesar dos cortes gerados pela recente crise econômica internacional. De 4,8\% do PIB, em 2008, passou a gastar 6,1\% do PIB em Educação em 2013, ficando em segundo lugar nos países da OCDE - Organizaçáo para a Cooperaçáo e o Desenvolvimento Econômico, em que o investimento real com a Educaçáo mais cresceu (OECD, 2016).

Os resultados de 2015 do PISA - Programme for International Student Assessment, que avalia os sistemas educacionais em todo o mundo testando as habilidades e o conhecimento de estudantes de 15 anos, demonstraram que a performance dos jovens portugueses melhorou desde 2006, tanto na Matemática quanto em Ciências, 
sendo que nesta última aparece acima da média dos países da OCDE. Se considerarmos que os sistemas educativos devem proporcionar uma Educação de qualidade para todos os seus alunos, o status social dos pais tem contribuído cada vez menos para as diferenças nos resultados dos jovens portugueses, o que significa um aumento visível na equidade social. Em termos de Inclusão, cerca de $98 \%$ dos alunos com deficiência ou necessidade específica de apoio são educados nas escolas regulares, sendo que o docente de Educação Especial faz parte dos quadros de escola, ao lado dos docentes de disciplinas como a Matemática, a Geografia, o Português ou outras. O Ensino Básico e obrigatório vai dos 6 aos 18 anos, ou seja, do $1^{\circ}$ ao $12^{\circ}$ ano de escolarização e toda a escola pública funciona em período integral (OECD, 2015).

Quanto à formação inicial de professores, esta acontece em nível de Mestrado, depois de cumprido um primeiro ciclo mínimo de 3 anos de estudos no Ensino Superior. No caso da Educação Especial, um professor pode concorrer a esta função apenas se, à data da matrícula para a especializaçáo ou mestrado em Educação Especial, tiver 5 anos de experiência docente comprovada. Fazendo as contas e não considerando possíveis interrupçóes neste percurso, um professor só conclui a especialização em Educação Especial passados 11 anos do seu ingresso no Ensino Superior: cinco anos até finalizar o primeiro Mestrado e tornar-se professor, mais cinco anos de docência, mais um ano de especializaçáo (ou mais dois anos, quando se trata de um curso de Mestrado em Educação Especial).

O panorama apresentado acima mostra, sem dúvida, uma realidade social, econômica e educativa bastante positiva neste momento. Isto não quer dizer que tudo seja positivo - muito longe disso! Numa investigação realizada em 10 escolas públicas de todo o país (LIMA-RODRIGUES, 2007), os professores e dirigentes entrevistados responderam que os recursos que estão à disposição das escolas são ainda limitados e poucos ou mal rentabilizados; afirmaram que o trabalho cooperativo entre os docentes é ainda raro e que sentem dificuldade em fazer uma verdadeira diferenciação pedagógica, sobretudo quando se trata da avaliação de todos os alunos; consideraram, ainda, que a formaçáo em geral tem uma grande distância entre o que lhes é ensinado e o que encontram na realidade das suas escolas. Um outro estudo evidencia que grande parte da metodologia utilizada nas formaçóes de professores está distante das metodologias que se espera que os formandos adotem nas suas práticas de sala de aula (RODRIGUES; LIMA-RODRIGUES, 2011). Mais recentemente, o mesmo relatório da OCDE, já referido anteriormente (OECD, 2016), demonstra que cerca de $23 \%$ dos diretores de escolas de $3^{\circ}$ ciclo $^{3}$ náo participaram de qualquer atividade de desenvolvimento profissional em 2013, o que é uma percentagem bastante elevada se comparada com a média da OCDE de $9 \%$. Apenas $11 \%$ dos professores participaram em alguma rede profissional, colocando Portugal nos mais baixos níveis de participação quando comparado com outros países.

Os cursos de formação permanente, tal como o que é analisado neste artigo, acontecem neste panorama social, econômico e educacional. Num país onde, embora as boas notícias chamem a atenção para um progresso consistente, há, ainda, um caminho longo e trabalhoso a percorrer. 


\section{O programa da formação}

"Pedagogias Expressivas em Educação Inclusiva" é uma formação contínua que foi desenhada com uma dupla intenção: por um lado, formar professores para a adoção de Pedagogias Expressivas nas suas práticas educativas e, por outro lado, utilizar Pedagogias Expressivas como metodologia para oferecer uma formação pessoal aos professores, com impacto na sua atuação profissional em favor de uma Educação mais inclusiva.

No programa do curso (PRÓ-INCLUSÃO, 2017), estão enunciados os seguintes objetivos:

1. Aprofundar conhecimentos sobre as Pedagogias Expressivas, seus fundamentos e seus efeitos na aprendizagem e no desenvolvimento humano.

2. Desenvolver habilidades de expressão e de comunicação verbal e não-verbal.

3. Aprimorar a capacidade de criar ou adaptar propostas, enfrentar desafios e solucionar problemas educacionais de forma criativa, inovadora e cooperativa, favorecendo a participação e o sucesso de todos os seus alunos.

Como conteúdos programáticos, o mesmo programa se propóe a fundamentar teoricamente as Pedagogias Expressivas e a construção coletiva do papel profissional no âmbito da Educação Inclusiva; apresentar os efeitos e a efetividade das Pedagogias Expressivas no desenvolvimento, na aprendizagem e na identidade estética e sociocultural dos alunos; proporcionar vivências expressivas originárias do drama, da dança, da música, da arte e da escrita criativa; promover a construção e/ou a adaptação de propostas expressivas e cooperativas em Educação Inclusiva e refletir sobre a avaliação em Pedagogias Expressivas.

Como metodologia, considerando os objetivos e a natureza dos conteúdos abordados, as aulas poderiam variar entre a tipologia prática e teórico/prática, com recurso a aulas dialogadas, dinâmicas cooperativas de grupo e vivência de pedagogias expressivas originárias da dança, da música, do drama, da arte, da escrita criativa e outras.

A avaliação previa a entrega de um relatório reflexivo, em que o formando deveria apresentar quais foram os principais efeitos desta formação no seu desenvolvimento pessoal e no desempenho do seu papel profissional. Para isso, deveriam levar em conta tanto os conteúdos em si, como também a forma como os mesmos foram abordados ao longo das aulas.

\section{Justificação}

Em alguns dos documentos que apresentam uma justificação para a oferta do curso "Pedagogias Expressivas em Educação Inclusiva" (OS TEMPLÁRIOS, 2017; PRÓ-INCLUSÃO, 2017, DIREÇÃO REGIONAL DE EDUCAÇÃO, 2017), encontram-se quatro ideias principais: 
1) Se a Educação Inclusiva sugere outras formas de ensinar e de aprender, implicando a flexibilização da organização escolar, das estratégias de ensino, da gestão dos recursos e dos currículos, então os métodos meramente expositivos e unidirecionais de ensino também precisam ser substituídos, em grande medida, por métodos ativos (LIMA, 2002). Os métodos ativos são centrados no aluno e envolvem toda a forma de aprender por meio da experiência, do diálogo, da investigação, da interação, enfim, do envolvimento implicado do aluno no seu processo de aprender.

2) Entre os métodos ativos estão as Pedagogias Expressivas (PE), entendidas como "formas de organização do trabalho pedagógico que valorizam as múltiplas possibilidades expressivas dos alunos, com ênfase na açáo, na interaçáo e nas expressôes artísticas" (LIMA-RODRIGUES; SANTOS; TRINDADE, 2016, 813p.). Utilizam recursos derivados da arte, do drama, da música, da dança e de outras formas de expressão, para que os alunos tenham um acesso mais universal ao currículo: para que estejam mais envolvidos nas tarefas e mais motivados para aprender e para cooperar; para que apreendam de formas mais variadas; para que expressem o que são e o que sabem de múltiplas maneiras, e para que desenvolvam competências pessoais e interpessoais imprescindíveis para os objetivos de uma Educaçáo Inclusiva (LIMA, 2004; LIMA-RODRIGUES, 2014a; SANTOS; LIMA-RODRIGUES, 2016).

3) Formar professores para a Inclusão não é o mesmo que formar profissionais para o uso de técnicas de ensino. As PE terão pouco efeito para a construçáo de uma Educação Inclusiva nas ações de um professor que mantém os valores e as crenças de uma "escola tradicional". A importância das atitudes, valores e crenças na formação de professores tem sido crescentemente apontada nos relatórios de muitos países (EADSEN, 2011), uma vez que a forma como os professores "sentem a Inclusão" influencia o sucesso que têm (ou não) na manutenção de princípios inclusivos nas suas aulas (MERGLER, 2016). Segundo FORLIN (2010), a Educação Inclusiva força diretamente os sistemas de crenças dos professores, incitando ou estimulando a mudança dos seus pensamentos mais profundos sobre o que é certo ou o que é justo. Sem dúvida, a mudança do sentimento e do pensamento está diretamente ligada à mudança da ação.

4) As PE na formação de professores favorecem o desenvolvimento pessoal e social dos formandos, uma vez que os mesmos são frequentemente colocados em situaçóes vivenciais que levam a uma tomada de consciência sobre si mesmo, sobre o outro e sobre os próprios valores e práticas da Educação Inclusiva (LIMA-RODRIGUES, 2014b). Não deixam o professor limitado a se expressar apenas de forma oral ou escrita, mas estimulam uma multiplicidade de expressóes verbais e não-verbais, individuais e coletivas, com as quais os professores normalmente estão pouco habituados ou tiveram uma formação deficitária neste sentido (UDVARI-SOLNER; KLUTH, 2008). Para além disso, as PE são um poderoso instrumento de avaliação e diagnóstico de processos educativos (de aprendizagem e de ensino), bem como de intervenção psicopedagógica decorrente desta avaliação (LIMA-RODRIGUES; SANTOS; TRINDADE, 2016).

Resumindo, o que justifica a realização de uma formação em Pedagogias Expressivas é possibilitar aos professores experiências que os tornem mais conscientes 
das variáveis pessoais que influenciam as suas ações educativas em favor da Inclusão. E o que justifica a publicação desta experiência é que, embora a evidência mostre que a formação de professores pareça influenciar as suas atitudes, valores e crenças, aparecem poucos exemplos que mostrem como realizar tais mudanças (EADSNE, 2011). $\mathrm{O}$ que faremos a seguir é mesmo isso: apresentaremos alguns exemplos de "como realizar tais mudanças". Não significa que apresentaremos receitas prontas e infalíveis, mas compartilharemos algumas das experiências vividas no curso, para que sirvam de inspiração para outras e melhores práticas de formação docente.

\section{"Bagunçando o coreto"}

Quando na aula inicial de apresentação nos sentamos, em mesas de trabalho dispostas da forma usual, como em qualquer sala de aula, estávamos longe de imaginar a quantidade de "desarrumação" que se iria operar, na nossa prática profissional diária, ao pôr em causa conceitos, preconceitos e rotinas letivas que fomos adquirindo ao longo do tempo. ${ }^{4}$

Mal termina a apresentação formal do programa do curso (número de formandos, listas de presença, horários, datas de entrega de trabalhos etc.), os formandos são imediatamente convidados a "bagunçar o coreto" 5 , removendo as mesas do lugar e ocupando o centro da sala e da aprendizagem. É assim que, intencionalmente, toda a formação segue a mesma ordem lógica da construção da inteligência: do concreto para o abstrato, do lúdico para o lógico, do sensório-motor para as operaçóes complexas, do ato para o pensamento...

O curso começa com algum quebra-gelo e com vários jogos sociométricos, que nos fazem reconhecer o grupo e as pessoas que o compóem, trazendo à tona aquilo que vincula umas pessoas às outras, ou que as afasta, ou que as isola. "Quem nasceu em Portugal? Quem tem um animal de estimaçáo? Quem torce para o Benfica? Quem pratica algum desporto regularmente? Quem teve um colega com deficiência quando estava na escola básica? Quem já privilegiou um aluno? Quem tem parentes próximos ou amigos íntimos com deficiência? Quem tem algum aluno com NEE ou deficiência? Quem tem alunos que não compreendem o português? Quem é professor 'do regular'? Quem é professor 'do especial'? Quem já foi reprovado alguma vez?”

As pessoas vão caminhando e juntando-se em subgrupos, conforme as suas respostas sejam "sim" ou "não". Por exemplo: "quem é professor de Inglês?" - quem "sim" junta-se com os outros num lado da sala, quem "não" vai para o lado oposto. Durante o jogo, os formandos são estimulados a ajudar a propor perguntas e, às vezes, a fazer a "leitura" do gráfico humano que resulta de uma pergunta, identificando, por exemplo, as percentagens de "sim" e "não", as médias, as modas ou as medianas. Ou podem criar gráficos de várias barras, se for necessário: "sim", "não", "talvez", "não sei”.

Quando o jogo termina, sem que se tenham dado muito conta, as pessoas já se olharam nos olhos, já gargalharam, já sabem quem cozinha mal, quem não torce para time nenhum, quem é professor do quê. Não há dúvida de que o elemento surpresa e a novidade, muito presentes nas PE, são um forte elemento motivador para a aprendizagem e uma forte garantia para uma interação mais profunda e frutífera para as pessoas de um mesmo grupo. 
A grande mais valia desta ação ${ }^{6}$ foi exatamente apontar diferentes e desafiadores caminhos.

$\mathrm{Na}$ esmagadora maioria dos encontros/convívios/sessões/aulas, fui agradavelmente, surpreendido.

Quando chega o momento da reflexão, o "coreto está táo bagunçado" que as pessoas já não estão engessadas nos seus cargos, nas suas funçôes ou nos seus títulos acadêmicos. Já não estão tấo fundidas com os seus "pré-conceitos" nem com as suas certezas. A intenção é que, neste momento, a possibilidade da dúvida sobre si mesmo e sobre a prática docente se instale e, para isso, é preciso que a dimensão pessoal se sobreponha à dimensão profissional ou social. Caso contrário, a reflexão provavelmente não cumprirá com a sua principal função que é a de "despertar". Acordar para a possibilidade de pensar diferente, de reconhecer que as experiências de toda a vida corroboram para desenhar o professor que cada um é, e de desconfiar que, talvez, uma chave importante para a construção de uma Educação mais inclusiva esteja dentro de cada um.

Ao compartilhar o que se pode extrair das situaçóes vividas neste simples jogo, há quem assuma o desconforto por ter ficado sozinho num determinado momento, ou contente por descobrir que era a única pessoa na resposta "não", ou surpreso por descobrir que, não ficou isolado na resposta "sim" a uma dada questão. Assim, os formandos vão tirando ilaçóes sobre o que se passou, tomando consciência da experiência pessoal de jogar e fazendo pontes com o que ensinam, a forma como ensinam, a quem ensinam e como se sentem aqueles a quem ensinam. Vão acordando para as formas subtis e disfarçadas de exclusão que acontecem com mais frequência do que conseguimos perceber. Para fortalecer os argumentos, usam conceitos como igualdade, equidade, inclusão, direitos humanos, exclusão e outros, recorrendo a autores como Ainscow (2016), Rodrigues $(2013$; 2016) e vários outros, fazendo com que a fundamentação teórica tome conta da discussão, sustentando ou confrontando o pensamento com base em evidências.

Raramente era preciso ir muito longe para que alguém do grupo referisse que a mesma lógica "pessoal > profissional" (leia-se: "experiência > teorização") deveria acontecer com os alunos nas escolas.

Confesso que fiquei decepcionada quando percebi que a teoria que eu tanto estudei sobre a aprendizagem dizia uma coisa e eu fazia outra.

Toda a açáo esteve ligada por um fio condutor que nos levava a pensar/refletir sobre a necessidade de mudança de paradigma face à escola. Isso implica necessariamente uma mudança radical de atitude na forma como trabalhamos com os nossos alunos, pares e comunidade em geral.

Quando me questiono sobre o(s) aspecto(s) mais positivo dessa formação, ainda que se torne difícil fazer essa seleção, destaco o facto de ter "sido ensinada" através das mesmas estratégias que devo/posso utilizar na minha prática profissional.

A primeira etapa da formação era destinada à vinculação entre o grupo, por um lado, e à definiçáo de conceitos, por outro lado. É importante deixar claro do que 
estamos falando quando falamos de Inclusão. Fortalecer a ideia mais ampla de Inclusão, enquanto uma Educação de qualidade e para todos os alunos, de uma escola que não precisa ser "regular" e de uma Educação que não precisa ser "Especial", como lembram Rix (2015), Slee (2011), Ainscow (2007) e muitos outros. Por isso, talvez as duas perguntas que os formandos mais responderam ao longo de toda a formação foram:

1) Quem estaria excluído desse momento da vossa aula, se dinamizassem uma atividade como esta?

2) Que adequaçôes possíveis e exequíveis poderiam fazer para que todos os vossos alunos participassem o maior tempo possível dessa vossa aula?

Desde logo, fomos confrontados com uma prática pedagógica que conduziu a uma total alteração do paradigma de como integrar em sala de aula, alunos com necessidades educativas especiais. Deste modo, foi-nos demonstrado, por exemplo, que em vez de se procurar realizar simultaneamente uma atividade geral de aula, e uma atividade específica para aluno(s) com necessidades educativas especiais, tudo poderia ocorrer numa atividade única de forma a integrar todos os alunos.

Num instante passaram-se noventa minutos de aula! No final da mesma foi difícil averiguar quem saiu mais satisfeito do pátio, se os alunos com a aula "diferente" e enriquecedora que tiveram, se eu pela utilização destas técnicas que me permitiram aferir que, efetivamente os alunos aprenderam.

As aulas seguintes destinavam-se às temáticas específicas do drama, da dança, da música e da arte.

$\mathrm{Na}$ área do drama, as experiências vividas estavam ligadas sobretudo ao sociodrama - técnica dramática cujo objetivo é investigar situaçóes-problema que acontecem na sociedade, através da ação dramática, para melhor compreendê-las e tentar solucioná-las (LIMA, 2004). Assim, para investigar a "Inclusão", por exemplo, um subgrupo construiria uma cena de escola que representasse "exclusão". O outro subgrupo representaria "Inclusão".

Durante a representação de cada grupo eram utilizadas várias técnicas do sociodrama, mas, principalmente, o solilóquio e a inversão de papéis.

No solilóquio, a cena era congelada e era solicitado a cada personagem que "pensasse em voz alta", funcionando como um amplificador do que se passa no íntimo da personagem. Numa cena de exclusão que se passou entre um professor e dois alunos, ouvimos os seguintes solilóquios:

- Professor: "Porque é que não vem buscar este rapaz da minha aula?! Era melhor para ele se estivesse com o professor do Especial e eu podia dar a minha aula sossegadinho!"

- Aluno sem deficiência: "Eu podia ajudar o meu colega, mas o professor não deixa! Não confia em mim!” 
- Aluno com deficiência: "Eu sei que eu sou um falhanço."

Neste momento, pedimos que professor e o aluno com deficiência invertessem os papéis. Quem estava a representar o professor passou a representar o aluno e vice-versa. E o solilóquio continuou:

- Aluno com deficiência: "Eu sei que sou um falhanço e o meu professor também é. Ele ainda mais do que eu! Esta escola não foi feita para mim."

No momento da reflexão, os formandos que assumiram algum papel eram os primeiros a falar, ainda como personagens: "eu, aluno com deficiência, senti raiva daquele professor que me queria longe dali", ou "eu sabia muito bem como poderia ajudar o meu colega porque o meu primo é assim também e eu lido lindamente com ele". Só depois os formandos "despiam-se" da personagem e compartilhavam a experiência do grupo "nas suas próprias peles". Claro, fazendo sempre pontes entre o pessoal e o profissional.

...as dinâmicas de grupo (...) fizeram com que trabalhasse e explorasse certos aspectos que não são hábito no meu quotidiano... dar voz a uma personagem, criar uma situação nova, a necessidade de ser criativa numa situação imediata. Seria o início daquilo que foi, para mim, uma autêntica surpresa.

A dança visava explorar quer as possibilidades expressivas do corpo, quer a interação entrepares e/ou a comunicação não-verbal. "Dançar o mais longe possível uns dos outros", "agora o mais perto possível", "dançar com o outro", "dançar contra o outro" "dançar baixo/grande/previsível/escondido/igual/feio"... Cada novo comando impunha um novo problema a resolver. As músicas escolhidas e os adereços utilizados (panos, tiras de cetim, chapéus) atiravam os formandos para estados de bem-estar, prazer e divertimento que, nos momentos de reflexão, eram considerados essenciais para eles próprios e para a relação pedagógica com os seus alunos (LIMA-RODRIGUES, 2014a). Também ressaltavam, entre outros aspectos, que a precisão dos gestos e das expressōes, querendo significar uma coisa e não outra, era algo que deveria fazer parte da essência da formação de professores, tanto mais em situaçôes onde a única comunicação possível é a não-verbal.

A criação de movimentos próprios ao som da música, o dançar com tecidos, brincar com adereços, fez-me por breves instantes sentir infantil, leve, sem responsabilidades nem preocupações. (...). É fulcral estarmos bem conosco se queremos que isso também aconteça com os outros e com a nossa interação. E isso é fundamental para podermos atingir os nossos objetivos, seja ao nível da lecionação das aulas, no relacionamento entrepares ou no nosso dia-a-dia no geral.

$\mathrm{Na}$ área da Música, investigamos a "história de vida musical" de cada um, relembrando as músicas que marcaram as diversas fases da vida e os momentos sociais, políticos e econômicos do país e do mundo naquela época, trazendo para a discussão conteúdos de história, de educação artística, de economia, entre outros. Outras vezes, solicitávamos aos subgrupos que compusessem uma pequena frase musical. Esta 
composição era então transposta para o papel, "desenhando" símbolos que representassem a sequência de sons (como se estivessem a escrever a partitura da música). Por fim, um subgrupo era desafiado a ler "a partitura simbólica" do outro. Ou, ainda, desafiamos um subgrupo a fazer uma improvisação com diversos instrumentos musicais, enquanto o outro subgrupo observava a improvisação e tomava nota dos ciclos de energia da improvisação, da alternância na motivação dos participantes, das lideranças que surgiam, da forma como cada um explorava (ou não) os instrumentos...

Estas experiências levaram a reflexóes interessantes, como o reconhecimento de que o ritmo da vida burocrática na escola pode atrapalhar o respeito ao ritmo de aprendizagem dos alunos, ou que os alunos que criam em conjunto uma partitura com símbolos pode compreender melhor a necessidade de existirem códigos comuns a um mesmo grupo social, como é o caso da língua portuguesa ou dos sinais de trânsito - para citar apenas alguns exemplos.

A diversidade, a individualidade, a criatividade e a liberdade são pilares essenciais na construção do indivíduo como um todo. Diferentes meios (drama, dança, música, jogos...) estimulam diferentes partes do cérebro, e com isto alargamos claramente as hipóteses de chegar a muito mais alunos de uma forma conjunta e cooperativa.

Por fim, a arte, destinada à experiência estética e sensorial, à exploração de componentes como a forma, o peso, a textura, a cor, a luz e a sombra, a bi e a tridimensionalidade, além dos símbolos e os seus múltiplos significados.

Neste âmbito, fica o exemplo da produção do livro "a minha vida de aprendiz". Com papéis coloridos e todo o tipo de material reciclável, a proposta era que cada um refletisse sobre o seu percurso de vida enquanto aprendiz, desde a entrada na escola até aquele momento formativo. Tinham, então, que determinar quais os momentos que, ao longo desse percurso, foram significativos o suficiente para serem considerados "um capítulo". Por fim, os formandos deveriam construir o livro utilizando exclusivamente símbolos criados pelos mesmos - não eram permitidas palavras, números nem imagens prontas recortadas de algum lugar. $\mathrm{O}$ livro poderia ter qualquer formato, ou seja, estavam livres para criar um livro que não fosse retangular, nem cujos capítulos fosse a passagem de folhas.

Não posso também deixar de referir como um aspecto que me foi particularmente potenciador de crescimento, a reflexáo crítica da própria maneira como a minha aprendizagem foi construída ao longo de toda a escolarização e de toda "a minha vida de aprendiz". Esta análise crítica que passou por diferentes situaçóes de jogo e culminou com a construção de uma quase biografia simbólica, permitiu-me não só uma análise crítica do processo, mas também uma reatribuição de significados.

... permitiu-me fazer parar e pensar um pouco em todas as experiências e dificuldades por que tenho passado ao longo destes 16 anos em que leciono.

Também me fez encarar a Educação Inclusiva de outra forma, como uma escola que respeita e valoriza todos os alunos. 
Assim, a "bagunça do coreto" ficava completa e o curso encerrava com os grupos a fazer uma imagem, com movimento e com som, mas sem palavras, que sintetizasse as experiências vividas nas 25 horas de formação em "Pedagogias Expressivas em Educação Inclusiva”.

Mais do que os registos fotográficos das pessoas bonitas que fizeram parte dessas sessóes, trouxe dentro uma fotografia mental do que cada coraçáo partilhou, ensinou, ampliou. Agradeço a todos e guardarei essas memórias para os dias em que as dúvidas tentarem beliscar as minhas certezas.

\section{Empurrar a inclusão}

O objetivo deste artigo foi mostrar um exemplo de como uma formação de professores pode mudar ou incitar/potenciar/estimular/impulsionar/acelerar a mudança de atitudes, em favor da Inclusão. Os excertos copiados dos relatórios dos formandos parecem mostrar que, realmente, há coisas que não se aprende nos livros. Durante as formaçóes, os momentos de partilha e reflexão mostraram que muitos ficavam espantados com a proposta de aprender movendo, de aprender em ação. Meyer e Young (2013) chegam a afirmar que o teatro é uma ferramenta "provocativa" de ensino. O mesmo acontece com todos os métodos ativos e expressivos: provocam a aprendizagem e, com isso, estimulam ou empurram a Inclusão.

Poderíamos, assim, sintetizar a avaliação desta experiência em três pontos:

1. Uma formação transformadora inicia e tem como alicerce a dimensão pessoal do formando. Ficou evidente, nos relatórios escritos e nas partilhas de ideias, que é preciso começar por "olhar para dentro de si", se o objetivo for integrar o desenvolvimento pessoal com o profissional.

2. Uma formação, ela própria "Inclusiva", deve promover a empatia e a possibilidade de os formandos se colocarem no papel do outro - dos vários "outros": alunos, pais, outros professores, líderes, comunidade, outros intervenientes educativos e até da sociedade ou do país. A empatia é assumida como sendo fulcral para uma prática profissional com valores inclusivos.

3. Uma formação "bagunçadora de coretos", que retira as pessoas do conforto e avança com o pensamento e a ação para a Inclusão, utiliza metodologias ativas, cooperativas e expressivas para que os formandos apreendam melhor e deem outros significados para os conceitos e práticas inclusivos. Às vezes, basta permitirmos que os alunos saltem para o centro da sala... e do processo de aprendizagem também!

...estava convencida que iria aprender diversas formas de organizar o meu trabalho, que essa açáo teria um contributo essencialmente na aquisição de diferentes metodologias de ensino que viriam a contribuir numa melhoria da minha prática pedagógica. Longe estava eu de imaginar que essa açáo se propunha a muito mais. Para trabalharmos bem para os outros, é necessário trabalharmos o "eu". 


\section{Referências}

AINSCOW, M. Struggles for Equity in Education: the selected works of Mel Ainscow. Oxon, UK: Routledge, 2016. 228p.

AINSCOW, M. Prefácio: a viragem inclusiva. In LIMA-RODRIGUES, L. et al. Percursos de Educaçáo Inclusiva em Portugal: dez estudos de caso. Lisboa: FEEI/FMH Ediçōes, 2007. p.13-19.

DIREÇÃO REGIONAL DE EDUCAÇÃO - REGIÃO AUTÓNOMA DA MADEIRA. Atividade Formativa: Pedagogias Expressivas em Educaçấo Inclusiva. Disponível em: <http://digital.gov-madeira.pt/interagir/ Forma\%C3\%A7\%C3\%A3o/tabid/212/mid/805/m494f/c35510-0ic522li337-449/Default.aspx?ctl=Crud. Acoes\&ContainerSrc $=\% 5 \mathrm{bS} \% 5 \mathrm{dContainers} \% 2 \mathrm{fGRM}$ _Interagir_CntLaranja\%2fCnt_Inf_D1_Edicao $>$. Acesso em: 02 maio 2017.

EUROPEAN AGENCY FOR DEVELOPMENT IN SPECIAL NEEDS EDUCATION - EADSEN. Formaçáo de professores para a Inclusão na Europa: desafios e oportunidades. Odense, Denmark: EADSEN, 2011. FORLIN, C. (Ed.) Teacher Education for Inclusion: changing paradigms and innovative approaches. Oxon, UK: Routledge, 2010. 259p.

INSTITUTE FOR ECONOMICS \& PEACE. Global Peace Index 2017: Measuring peace in a complex world. Sidney: Institute for Economics \& Peace, 2017. Disponível em: <http://visionofhumanity.org/app/uploads/2017/06/GPI-2017-Report-1.pdf>. Acesso em: 20 maio 2017.

LIMA, L.M.S. O psicodrama pedagógico na formação de professores. Revista de Ciências da Educação, Centro Universitário Salesiano de Sáo Paulo, São Paulo, v. 03, n. 5, p. 141-152, 2002.

LIMA, L.M.S. O drama na formaçâo de professores. In: LIMA, L.M.S.; LISKE, L. (Org.) Para aprender no ato: técnicas dramáticas na Educação. Sáo Paulo: Ágora, 2004. p. 40-66.

LIMA-RODRIGUES, L. et al. Percursos de Educaçáo Inclusiva em Portugal: dez estudos de caso. Lisboa: FEEI/FMH Ediçôes, 2007. 205p.

LIMA-RODRIGUES, L.M.S. Sociodrama, teacher education and inclusion. In: WIENER, R; ADDERLEY, D.; KIRK, K. (ed.). Sociodrama in a Changing World. UK: Lulu, 2011.

LIMA-RODRIGUES, L.M.S. Com todo o prazer! As atividades expressivas na Educação das crianças. In: OLIVEIRA, G. et al. (Ed.) Educar crianças, grandes desafios: Como enfrentar? Petrópolis: Vozes, 2014a. p.64-82.

LIMA-RODRIGUES, L.M.S. Developing the role of inclusive teachers through sociodrama. In: EMBRACING INCLUSIVE APPROACHES FOR CHILDREN AND YOUTH WITH SPECIAL EDUCATION NEEDS CONFERENCE, 2014, Braga. Proceedings... Braga: CIEd/Institute of Education, 2014b. p.37-40. Disponível em: < file:///C:/Users/elisa/Downloads/Proceedings_Braga_2014.pdf>. Acesso em: 02 maio 2017.

LIMA-RODRIGUES, L.M.S.; SANTOS, G.D.; TRINDADE, A.R. Pedagogias Expressivas na Formação de Professores. JORSEN - Journal of Research in Special Educational Needs, v. 16, n. s1, p.813-817, 2016.

MERGLER, A., et al. Inclusive Values: Exploring the Perspectives of Pre-Service Teachers. Australian Journal of Teacher Education, v. 41, n.4, p.19-38, Apr. 2016. Disponível em: <httpp://ro.ecu.edu.au/ajte/vol41/ iss $4 / 2>$. Acesso em: $12 \mathrm{dez} .2016$.

MEYER, M. J.; YOUNG, D.C. TAR (Theatre As Representation) as a provocative teaching tool in school administration: a dramatized inclusive classroom scenario. Canadian Journal of Educational Administration and Policy, Canada, n.142, p.69-89, July 8, 2013.

OECD. Education at a Glance 2016: OECD Indicators. Paris: OECD Publishing, 2016. Disponível em: < http://www.oecd.org/edu/education-at-a-glance-19991487.htm>. Acesso em: 20 maio 2017.

OECD. PISA: Programme for International Student Assessment - PISA 2015 Portugal. Disponível em: <http://www.compareyourcountry.org/pisa/country/prt>. Acesso em: 07 abr. 2017.

ORGANIZAÇÃO DAS NAÇŌES UNIDAS - ONU. Convençáo sobre os direitos das pessoas com deficiência. 2006.

OS TEMPLÁRIOS. Pedagogias Expressivas em Educaçáo Inclusiva. Disponível em: <http://www.cftemplarios.com/attachments/article/211/AN.pdf>. Acesso em: 02 maio 2017.

PRÓ-INCLUSÃO: ASSOCIAÇÃO NACIONAL DE DOCENTES DE EDUCAÇÃO ESPECIAL. Formaçáo: pedagogias expressivas em educação inclusiva I. Disponível em: <http://cfpinandee.weebly.com/uploads/1/6/4/6/16461788/sinopse_-_pedagogias_expressivas_na_educa\%C3\%87\%C3\%82o_inclusiva_i.pdf $>$. Acesso em: 02 maio 2017. 
RIX, J. Must Inclusion be Special? Rethinking Educational Support Within a Community of Provision. Oxon, UK: Routledge, 2015. 216p.

RODRIGUES, D. Equidade e educaçáo inclusiva. Porto, Portugal: Profediçōes, 2013. 150p.

RODRIGUES, D. Direitos humanos e inclusão. Porto, Portugal: Profediçōes, 2016. 204p.

RODRIGUES, D.; LIMA-RODRIGUES, L.M.S. Formação de professores e Inclusão: como se reformam os reformadores? Educar em Revista, Curitiba, n. 41, jul./set., p.41-60, 2011.

SANTOS, G.D.; LIMA-RODRIGUES, L.M.S. Expressive arts: embodying inclusive teachers. JORSEN Journal of Research in Special Educational Needs, v.16, n. s1, p.506-509, 2016.

SLEE, R. The irregular school: exclusion, schooling and inclusive education. Oxon, UK: Routledge, 2011. $219 \mathrm{p}$.

UDVARI-SOLNER, A.; KLUTH, P. Joyful Learning: active and collaborative learning in inclusive classrooms. California: Corwin Press, 2008.

\section{Notas}

${ }^{1}$ No Brasil: Ensino Médio.

${ }^{2}$ No Brasil: fonoaudiólogos.

${ }^{3}$ No Brasil: anos finais do Ensino Fundamental.

${ }^{4}$ Todas as citações apresentadas em parágrafo destacado são literais e foram extraídas dos relatórios de avaliação apresentados pelos formandos do curso "Pedagogias Expressivas em Educação Inclusiva”, nas suas 10 ediçốes.

${ }^{5}$ Expressão popular utilizada aqui no sentido de "agitar", "desinstalar", "tirar ou sair do lugar de conforto".

6 "Ação de formação" é uma expressão que, em Portugal, refere-se a um curso breve ou a uma formaçấo contínua de curta duração.

\section{Correspondência}

Luzia Mara Silva Lima-Rodrigues - Vindas Educação Internacional: Rua Baltazar Lopes no 4 - 2o Esquerdo. 2795-030, Linda-a-Velha, Portugal.

E-mail: luzia@vindas.pt

Recebido em 11 de julho de 2017

Aprovado em 11 de agosto de 2017 